\title{
Пластичность и особенности общей и согласованной изменчивости признаков в популяциях Delphinium litwinowii Sambuk
}

\section{Plasticity and peculiarities of general and consistent variability of features in Delphinium litwinowii Sambuk populations}

\author{
Богослов А. В., Кашин А. С., Шилова И. В., Крицкая Т. А., Пархоменко А. С., Гребенюк Л. В. \\ Bogoslov A. V., Kashin A. S., Shilova I. V., Kritskaya T. A., Parhomenko A. S., Grebenyuk L. V. \\ Саратовский национальный исследовательский государственный университет им. Н. Г. Чернылевского, \\ 2. Саратов, Россия.E-mail: dandelioncave@mail.ru \\ Saratov State University, Saratov, Russia
}

\begin{abstract}
Peфepam. На основании данных, полученных в ходе камеральных и полевых исследований 2017-2018 гг., нами были изучены пластичность и изменчивость морфологических показателей особей четырёх популяций Delphinium litwinowii Sambuk. Было установлено, что уровень изменчивости различных признаков D. litwinowii варьировал от среднего до очень высокого. Экологические показатели включали один признак. К эколого-биологическим индикаторам не относился ни один показатель. Биологические показатели включали 14 признаков, отражающих состояние вегетативной и генеративной сфер морфологической структуры растений. Группа генотипических признаков была представлена 14 генеративными и вегетативными признаками. Индекс пластичности разных морфометрических параметров в общем по всем популяциям за период исследования менялся от среднего до высокого уровня. В целом, в ряду убываний значений Ір от максимального до минимального наблюдается заметное постепенное снижение значений $\mathrm{Cv}$.
\end{abstract}

Ключевые слова. Общая и согласованная изменчивость, пластичность, Delphiniun litwinowii.

Summary. Based on data obtained in the course of laboratory and field studies in 2017-2018, we examined the plasticity and variability of the morphological parameters of individuals in four populations of Delphinium litwinowii Sambuk. It was found that the level of variability of different features of $D$. litwinowii varied from medium to very high. Environmental indicators included one feature. No features were related to ecological-biological indicators. Biological indicators included 14 features reflecting the state of the vegetative and generative spheres of the morphological structure of plants. The group of genotypic characters was represented by 14 generative and vegetative features. The plasticity index of different morphometric parameters for all populations in total over the study period varied from medium to high levels. In general, in a series of decreases in Ip values, from maximum to minimum, a noticeable gradual decrease in $\mathrm{Cv}$ values is observed.

Keywords. Common and consistent variability, Delphiniun litwinowii, plasticity.

Важной диагностической характеристикой оценки общего состояния ценопопуляций (ЦП), а также основой для определения виталитеной структуры является оценка изменчивости, общей и согласованной, морфологических параметров особей, составляющих конкретные ЦП. Не менее важно выяснение пластичности изучаемых морфометрических характеристик. Остро данный вопрос стоит для редких видов растений, каковым и является представитель семейства лютиковые (Ranunculaceae) - живокость Литвинова (Delphinium litwinowii Sambuk).

Живокость Литвинова - многолетнее короткокорневищное травянистое растение высотой 60 150 см, эндемик умеренной зоны Восточной Европы. Ареал вида охватывает территорию от бассейна Оки до Полтавской, Воронежской и Саратовской областей на юге, на востоке вид доходит до Южного Урала. (Цвелёв, 1996, 2001). Вид занесен в Красную книгу Воронежской области (Агафонов, 2011) с категорией 2 (сокращающийся). В Красные книги Пензенской (Чистякова, 2013) и Тамбовской (Усова, 
2002) областей занесён Delphinium cuneatum Stev. ex DC., который нередко понимается широко и включает D. litwinowii (The Plant List, 2013).

Нами было изучено четыре ЦП D. litwinowii: две - в 2017-2018 гг. в Пензенской обл. на территории заповедника «Приволжская лесостепь»; одна - в 2018 г. в Воронежской обл., на территории памятника природы «Степные склоны у с. Владимировка»; одна - в 2018 г. в Тамбовской обл., на территории памятника природы «Осиновый овраг».

В качестве учетной единицы принимали особи генеративного зрелого онтогенетического состояния (g2) (Злобин, 1989). Возрастные состояния генеративных особей определяли согласно указаниям Н. И. Фёдорова (2003). В каждой популяции у 30 случайно выбранных растений измерялись следующие количественные признаки: высота растения, диаметр растения, число генеративных побегов, длина генеративного побега, число листьев на генеративном побеге, длина междоузлия, диаметр стебля в середине третьего снизу междоузлия, число цветков в соцветии, длина соцветия, число паракладиев первого порядка, длина наиболее развитого паракладия, длина и ширина чашелистика, длина и ширина шпорца, длина листовой пластины, длина нерасчленённой части листовой пластины, длина центрального сегмента средней лопасти, ширина листовой пластины, ширина основания центрального сегмента, максимальная ширина средней лопасти, ширина основания средней лопасти, длина и ширина черешка, длина и ширина прицветника, длина и ширина прицветничка, длина цветоножки.

Оценку изменчивости изучаемых признаков проводили по значению коэффициента вариации $(\mathrm{Cv}, \%)$ с учётом шкалы изменчивости для травянистых растений (Мамаев, Чуйко, 1975): $\mathrm{Cv}<7 \%-$ очень низкий, $\mathrm{Cv}=7-15 \%$ - низкий, $\mathrm{Cv}=16-25 \%$ - средний, $\mathrm{Cv}=26-35 \%$ - повышенный, $\mathrm{Cv}=36-$ $50 \%$ - высокий, $\mathrm{Cv}>50 \%$ - очень высокий уровень.

Оценку среднего уровня связей между признаками проводили, используя квадрат коэффициента корреляции $\mathrm{r}^{2}$, усредненный по отдельным признакам $\left(\mathrm{R}^{2} \mathrm{ch}\right)$. По коэффициентам $\mathrm{Cv}$ и $\mathrm{R}^{2} \mathrm{ch}$ проведён сравнительный анализ общей и сопряженной изменчивости признаков D. litwinowii. Согласно методике выделяются четыре группы системных индикаторов: 1) экологические , 2) эколого-биологические, 3) биологические, 4) генотипические. (Ростова, 2002).

Для оценки пластичности признака использовали индекс фитоценотической пластичности (Ip), под которым понимается отношение амплитуды пластичности к коэффициенту свободного развития (Злобин и др., 2013). Значения этого индекса лежат в интервале от 0 до 1. Чем ближе к единице, тем выше уровень пластичности рассматриваемого признака.

Результаты измерений и подсчётов обрабатывались с помощью программ «Microsoft Excel 2007», «Statistica 13.0» и «Past 3.0» (Hammer et al., 2001).

По результатам исследования структуры морфологической изменчивости, проведенного в популяциях D. litwinowii по 29 количественным морфологическим признакам, в группу экологических системных индикаторов (рис. 1, I), в большей степени зависящих от условий внешней среды и слабо связанных с изменениями других признаков, попал лишь один признак - число генеративных побегов (3). К эколого-биологическим системным индикаторам (рис. 1, II), т.е. признакам, отражающим согласованную изменчивость особей в неоднородной среде, не отнесён ни один из учтённых морфометрических показателей. К группе генотипических системных индикаторов (рис. 1, III) отнесены: диаметр куста (2), число листьев на генеративном побеге (5), длина междоузлия (6), длина чашелистика (12), ширина чашелистика (13), длина шпорца (14), ширина шпорца (15), длина нерасчленённой части листовой пластины (17), ширина основания средней лопасти (22), длина прицветника (25), ширина прицветника (26), длина прицветничка (27), ширина прицветничка (28), длина цветоножки (29). Оставшиеся признаки отнесены к группе биологических системных индикаторов (рис. 1, IV), в меньшей степени зависящих от условий среды, но обладающих общей согласованной изменчивостью, являясь при этом ключевыми для всей морфологической структуры особи: высота растения (1), длина генеративного побега (4), диаметр стебля в середине третьего снизу междоузлия (7), число цветков в соцветии (8), длина соцветия (9), число паракладиев первого порядка (10), длина наиболее развитого паракладия (11), длина листовой пластины (16), длина центрального сегмента средней лопасти (18), ширина листовой пластины (19), ширина основания центрального сегмента (20), максимальная ширина средней лопасти (21), длина черешка (23), ширина черешка (24). 


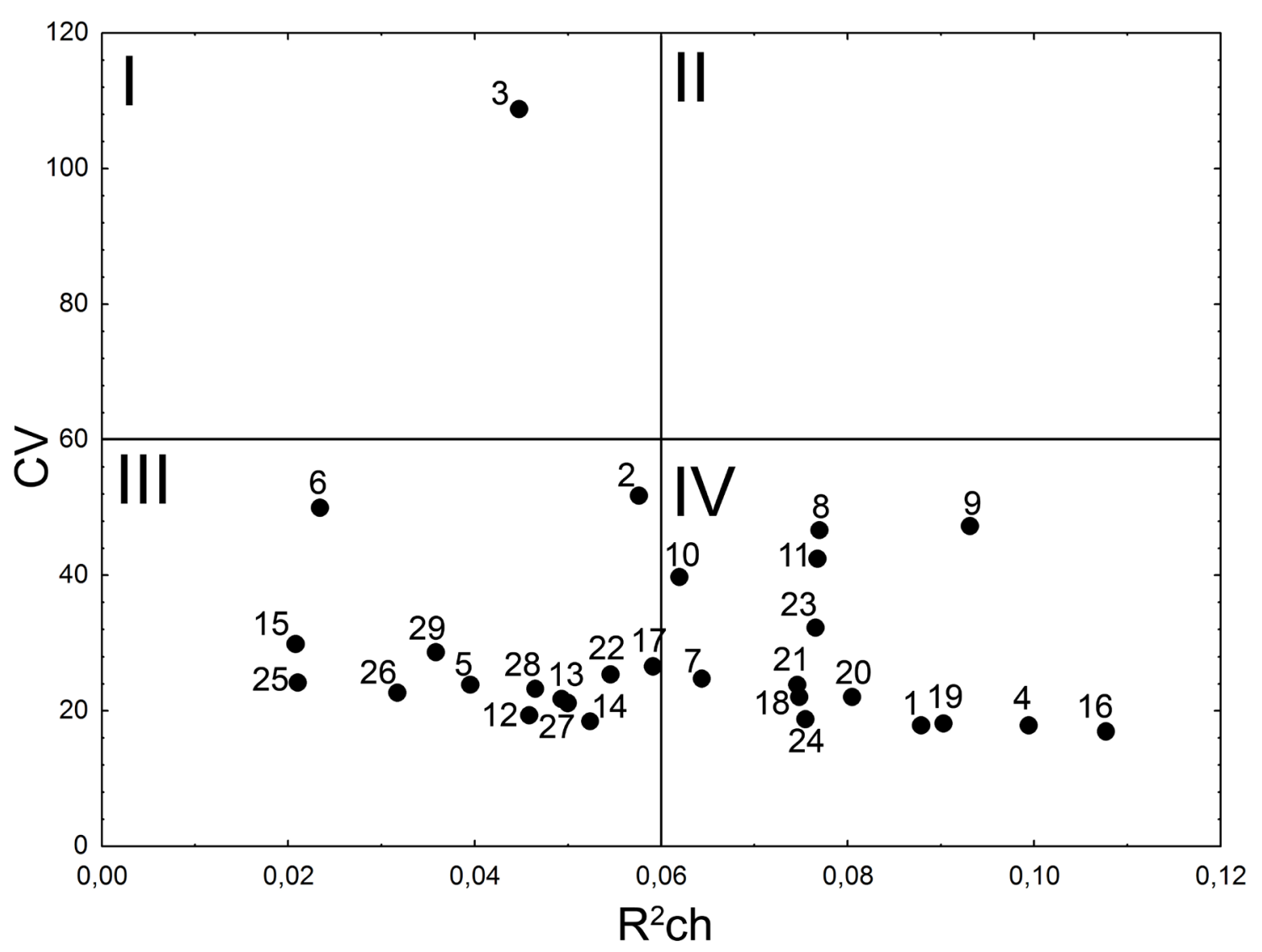

Рис. 1. Ординация морфологических параметров D. litwinowii по структуре морфологической изменчивости: 1 - высота растения; 2 - диаметр растения; 3 - число генеративных побегов; 4 -длина генеративного побега; 5 - число листьев на генеративном побеге; 6 - длина междоузлия; 7 - диаметр стебля в середине третьего снизу междоузлия; 8 - число цветков в соцветии; 9 - длина соцветия; 10 - число паракладиев первого порядка; 11 длина наиболее развитого паракладия; 12 - длина чашелистика; 13 - ширина чашелистика; 14 - длина шпорца; 15 - ширина шпорца; 16 - длина листовой пластины; 17 - длина нерасчленённой части листовой пластины; 18 - длина центрального сегмента средней лопасти; 19 - ширина листовой пластины; 20 - ширина основания центрального сегмента средней лопасти; 21 -максимальная ширина средней лопасти; 22 - ширина основания средней лопасти; 23 - длина черешка; 24 - ширина черешка; 25 - длина прицветника; 26 - ширина прицветника; 27 - длина прицветничка; 28 - ширина прицветничка; 29 - длина цветоножки. Группы системных индикаторов: I - экологические; II - эколого-биологические; III - генотипические; IV - биологические.

Уровень изменчивости у разных признаков D.litwinowii варьировал от среднего до очень высокого (табл.). Ни у одного из рассматриваемых признаков уровень изменчивости не опускался до низкого и очень низкого. Средним уровнем изменчивости характеризовались высота растения, длина генеративного побега, число листьев на генеративном побеге, диаметр стебля в середине третьего снизу междоузлия, длина чашелистика, ширина чашелистика, длина шпорца, длина листовой пластины, длина центрального сегмента средней лопасти, ширина листовой пластины, ширина основания центрального сегмента, максимальная ширина средней лопасти, ширина основания средней лопасти, ширина черешка, длина прицветника, ширина прицветника, длина прицветничка, ширина прицветничка. Для ширины шпорца, длины нерасчленённой части листовой пластины, длины черешка и длины цветоножки отмечен повышенный уровень изменчивости. Высокой изменчивостью отличались длина междоузлия, число цветков в соцветии, длина соцветия, число паракладиев первого порядка, длина наиболее развитого паракладия. Очень высокой была изменчивость у диаметра куста и числа генеративных побегов.

Индекс пластичности разных морфометрических параметров в целом по всем популяциям за период исследований менялся от среднего до высокого уровня (рис. 2). Наиболее пластичными в боль- 
шинстве своём оказались показатели вегетативной и генеративной части растения: число генеративных побегов (3), длина междоузлия (6), число паракладиев первого порядка (10), число цветков в соцветии (8), длина соцветия (9), длина черешка (23), длина наиболее развитого паракладия (11), диаметр куста (2) (Ip - от 0,95 до 0,88$)$, менее пластичными (Ip - от 0,79 до 0,64$)$ - большинство параметров листовой пластины, а также некоторые генеративные показатели: длина нерасчленённой части листовой пластины (17), длина цветоножки (29), диаметр стебля в середине третьего снизу междоузлия (7), максимальная ширина средней лопасти (21), ширина основания средней лопасти (22), ширина прицветника (26), число листьев на генеративном побеге (5), длина прицветника (25), длина шпорца (14), ширина основания центральной доли (20), ширина чашелистика (13), ширина прицветничка (28), длина центрального сегмента средней лопасти (18), длина прицветничка (27), длина чашелистика (12), ширина листовой пластины (19). Наименее пластичны (Ip - от 0,58 до 0,57) параметры листовой пластины: длина листовой пластины (16) и ширина черешка (24), и вертикальной структуры растения: высота растения (1) и длина генеративного побега (4).

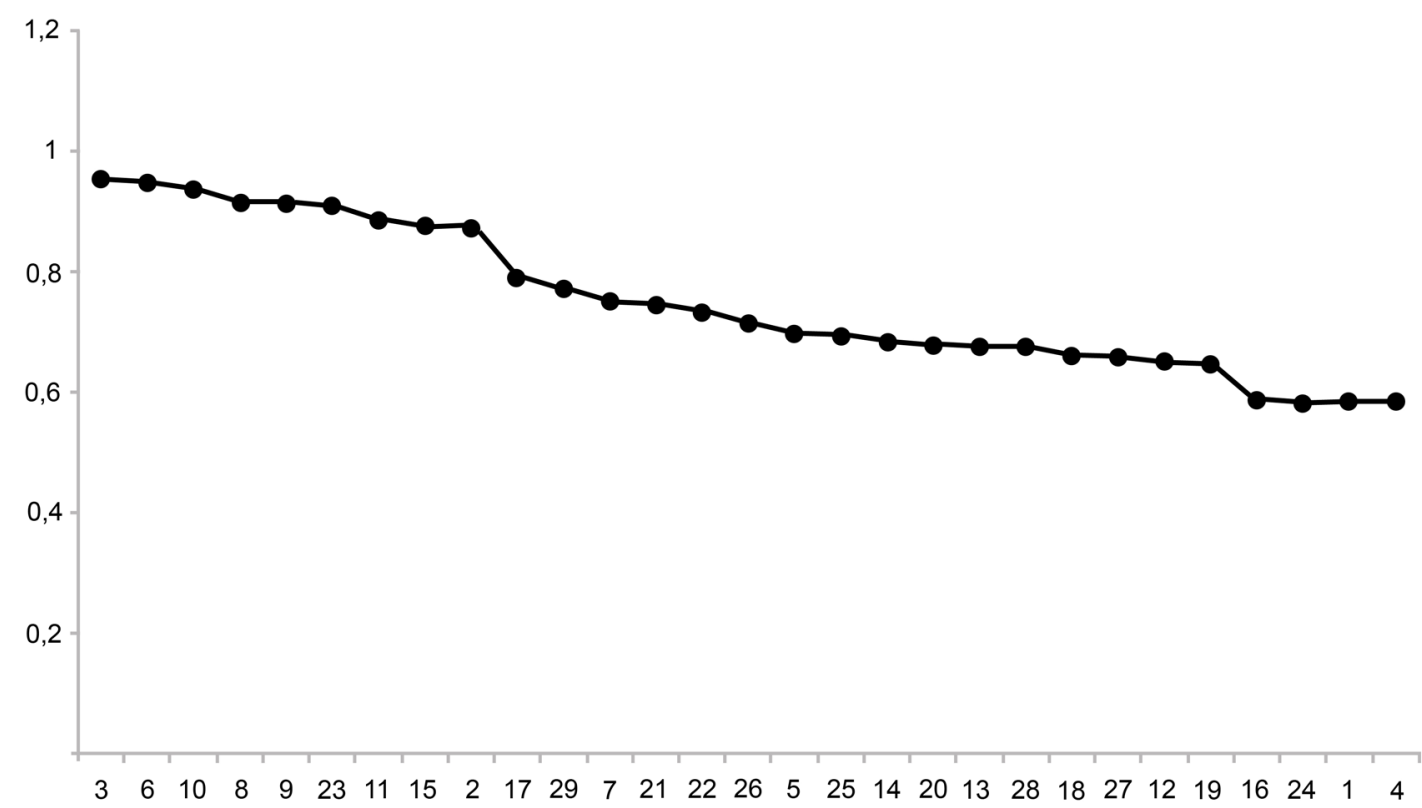

Рис. 2. Показатели пластичности морфометрических параметров Delphinium litwinowii (по оси абсцисс): 3 - число генеративных побегов; 6 - длина междоузлия; 10 - число паракладиев первого порядка; 8 - число цветков в соцветии; 9 - длина соцветия; 23 - длина черешка; 11 - длина наиболее развитого паракладия; 15 - длина шпорца; 2 - диаметр куста; 17 - длина нерасчленённой части листовой пластины; 29 - длина цветоножки; 7 - диаметр стебля в середине третьего снизу междоузлия; 21 - максимальная ширина средней лопасти; 22 - ширина основания средней лопасти; 26 - ширина прицветника; 25 - длина прицветника; 5 - число листьев на генеративном побеге; 14 - длина шпорца; 20 - ширина основания центрального сегмента средней лопасти; 13 - ширина чашелистика; 28 - ширина прицветничка; 18 - длина центрального сегмента средней лопасти; 27 -длина прицветничка; 12 длина чашелистика; 19 - ширина листовой пластинки;16 - длина листовой пластинки;24 - ширина черешка; 1 высота растения; 4 - длина генеративного побега. Индекс пластичности (ось ординат).

Из сравнительного анализа значений коэффициента вариации и индекса пластичности следует, что, по большинству признаков значения коэффициентов вариации прямо пропорциональны значениям индекса пластичности (табл.). Так, максимальному значению $\mathrm{Cv}(108,80)$ у числа генеративных побегов соответствует максимальное значение $\mathrm{I}_{\mathrm{p}}(0,95)$. В целом, в ряду убываний значений Ір от максимального к минимальному наблюдается постепенное снижение значений $\mathrm{Cv}$.

Благодарности. Исследование частично выполнено за счёт средств проекта РФФИ № 18-3400061. 
Таблица

Изменчивость и пластичность признаков Delphinium litwinowii

\begin{tabular}{|c|c|c|c|c|}
\hline Признаки & $\frac{X c p \pm S x}{\min -\max }$ & $\begin{array}{c}\text { Индекс } \\
\text { пластично- } \\
\text { сти I }{ }_{\mathrm{p}} \\
\end{array}$ & $\begin{array}{c}\text { Коэффициент } \\
\text { вариации } \\
\text { (Cv ), \% } \\
\end{array}$ & $\begin{array}{c}\text { Уровень } \\
\text { изменчивости }\end{array}$ \\
\hline Высота растения, см & $\frac{143,80 \pm 2,38}{85,0-200,0}$ & 0,58 & 18,0 & средний \\
\hline Диаметр куста, см & $\frac{77,94 \pm 3,73}{25,0-200,0}$ & 0,88 & 52,0 & очень высокий \\
\hline Число генеративных побегов, шт. & $\frac{5,09 \pm 0,51}{2,0-44,0}$ & 0,95 & 108,76 & очень высокий \\
\hline Длина генеративного побега, см & $\frac{147,16 \pm 2,46}{85,0-200,0}$ & 0,58 & 18,16 & средний \\
\hline Число листьев на генеративном побеге, шт. & $\frac{32,47 \pm 0,72}{16,0-53,0}$ & 0,70 & 24,06 & средний \\
\hline Длина междоузлия, см & $\frac{4,43 \pm 0,20}{1,0-20,0}$ & 0,95 & 50,20 & высокий \\
\hline $\begin{array}{l}\text { Диаметр стебля в середине третьего снизу } \\
\text { междоузлия, мм }\end{array}$ & $\frac{9,56 \pm 0,22}{4,17-16,86}$ & 0,75 & 24,96 & средний \\
\hline Число цветков в соцветии, шт. & $\frac{74,86 \pm 3,24}{16,0-189,0}$ & 0,92 & 46,80 & высокий \\
\hline Длина соцветия, см & $\frac{35,78 \pm 1,56}{9,0-105,0}$ & 0,91 & 47,34 & высокий \\
\hline Число паракладиев первого порядка, шт. & $\frac{6,34 \pm 0,23}{1,0-16,0}$ & 0,94 & 39,90 & высокий \\
\hline Длина наиболее развитого паракладия, см & $\frac{15,15 \pm 0,60}{4,0-35,0}$ & 0,88 & 42,67 & высокий \\
\hline Длина чашелистика, мм & $\frac{9,70 \pm 0,18}{5,59-15,56}$ & 0,64 & 19,63 & средний \\
\hline Ширина чашелистика, мм & $\frac{6,86 \pm 0,14}{3,72-11,54}$ & 0,68 & 21,86 & средний \\
\hline Длина шпорца, мм & $\frac{13,10 \pm 0,22}{9,91-21,95}$ & 0,68 & 18,48 & средний \\
\hline Ширина шпорца, мм & $\frac{3,12 \pm 0,09}{1,21-9,74}$ & 0,88 & 30,05 & повышенный \\
\hline Длина листовой пластины, мм & $\frac{92,41 \pm 1,46}{57,1-135,15}$ & 0,58 & 17,01 & средний \\
\hline $\begin{array}{l}\text { Длина нерасчленённой части листовой } \\
\text { пластины, мм }\end{array}$ & $\frac{20,35 \pm 0,50}{7,83-37,74}$ & 0,79 & 26,57 & повышенный \\
\hline $\begin{array}{l}\text { Длина центрального сегмента средней } \\
\text { лопасти, мм }\end{array}$ & $\frac{45,64 \pm 0,95}{26,15-77,52}$ & 0,66 & 22,24 & средний \\
\hline Ширина листовой пластины, мм & $\frac{129,30 \pm 2,21}{71,22-196,0}$ & 0,64 & 18,33 & средний \\
\hline $\begin{array}{l}\text { Ширина основания центрального сегмента } \\
\text { средней лопасти, мм }\end{array}$ & $\frac{11,72 \pm 0,24}{6,53-20,33}$ & 0,68 & 22,08 & средний \\
\hline $\begin{array}{l}\text { Максимальная ширина средней лопасти, } \\
\text { мм }\end{array}$ & $\underline{42,03 \pm 0,94}$ & 0,74 & 23,96 & средний \\
\hline Ширина основания средней лопасти, мм & $\frac{11,09 \pm 0,26}{4,76-17,90}$ & 0,73 & 25,41 & средний \\
\hline Длина черешка, мм & $\frac{74,14 \pm 2,25}{13,31-149,0}$ & 0,91 & 32,55 & повышенный \\
\hline Ширина черешка, мм & $\frac{1,89 \pm 0,03}{1,24-2,90}$ & 0,57 & 18,78 & средний \\
\hline
\end{tabular}


Таблица (окончание)

\begin{tabular}{|l|c|c|c|c|}
\hline \multicolumn{1}{|c|}{ Признаки } & $\frac{\mathrm{Xcp} \pm \mathrm{Sx}}{\min -\mathrm{max}}$ & $\begin{array}{c}\text { Индекс } \\
\text { пластично- } \\
\text { сти I }\end{array}$ & $\begin{array}{c}\text { Коэффициент } \\
\text { вариации } \\
(\mathrm{Cv}), \%\end{array}$ & $\begin{array}{c}\text { Уровень } \\
\text { изменчивости }\end{array}$ \\
\hline Длина прицветника, мм & $\frac{9,68 \pm 0,23}{5,60-18,35}$ & 0,69 & 24,16 & средний \\
\hline Ширина прицветника, мм & $\frac{2,42 \pm 0,05}{1,07-3,78}$ & 0,72 & 22,96 & средний \\
\hline Длина прицветничка, мм & $\frac{6,55 \pm 0,13}{3,69-10,80}$ & 0,66 & 21,30 & средний \\
\hline Ширина прицветничка, мм & $\frac{2,24 \pm 0,05}{1,24-3,84}$ & 0,68 & 23,55 & средний \\
\hline Длина цветоножки, мм & $\frac{16,72 \pm 0,45}{8,22-36,21}$ & 0,77 & 28,75 & повышенный \\
\hline
\end{tabular}

\section{ЛИТЕРАТУРА}

Аzафонов В. А. Живокость Литвинова - Delphinium litwinowii Sambuk // Красная книга Воронежской области: в 2 т. Т. 1: Растения. Лишайники. Грибы / науч. ред. В. А. Агафонов. - Воронеж: МОДЭК, 2011. - С. 171-172.

Злобин Ю. $\boldsymbol{A}$. Принципы и методы изучения ценотических популяций растений. - Казань: Изд-во Казанского университета, 1989. - $146 \mathrm{c}$.

Злобин Ю. А., Скляр В. Г., Клименко А. А. Популяции редких видов растений: теоретические основы и методика изучения. - Сумы: Университетская книга, 2013. - 439 с.

Мамаев $\boldsymbol{C}$. А., Чуйко Н. М. Индивидуальная изменчивость признаков листьев у дикорастущих видов костяники // Индивидуальная эколого-географическая изменчивость растений. - Свердловск: УрНЦ АН СССР, 1975. - C. 114-118.

Ростова Н. С. Корреляции: структура и изменчивость. - СПб.: Изд-во С.-Петерб. ун-та, 2002. - 308 с.

Усова. Г. С. Живокость клиновидная - Delphinium cuneatum Stev. ex DC. // Красная книга Тамбовской области: Растения, лишайники, грибы. - Тамбов: ИЦ Тамбовполиграфиздат, 2002. - С. 135.

Фёдоров Н. И. Род Delphinium L. на Южном Урале: экология, популяционная структура и биохимические особенности. - Уфа: Гилем, 2003. - 149 с.

Цвелев, Н. Н. О некоторых родах семейства лютиковых (Ranunculaceae) в Восточной Европе // Бот. журн., 1996. - Т. 81, № 12. - С. 112-122.

Цвелев Н. Н. Род живокость Delphinium L // Флора Восточной Европы. - СПб.: Мир и семья; Изд-во СПХФА, 2001. - T. 10. - C. 66-74.

Чистякова A. A. Живокость клиновидная Delphinium cuneatum Stev. ex DC. // Красная книга Пензенской области. Том 1. Растения и грибы / Науч. ред. А. И. Иванов. - Пенза: Пензенская правда, 2002. - С. 186.

Hammer O., Harper D. A. T., Ryan P. D. PAST: Paleontological Statistics software package for education and data analysis // Palaeontological Electronica, 2001. - Vol. 4, №1. - P. 1-9.

The Plant List. 2013. URL: http://www.theplantlist.org/tp11.1/record/kew-2760002 (Дата обращения 15.03.2019). 